\title{
Cerebrovascular Manifestations of Neurosarcoidosis: An Underrecognized Aspect of the Imaging Spectrum
}

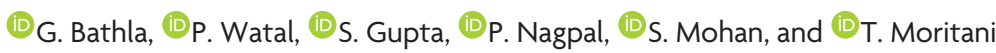

\begin{abstract}
SUMMARY: Involvement of the central nervous system by sarcoidosis, also referred to as neurosarcoidosis, is seen clinically in about $5 \%$ of patients with systemic disease. CNS involvement most frequently affects the leptomeninges and cranial nerves, though the ventricular system, brain parenchyma, and pachymeninges may also be involved. Even though the involvement of the intracranial vascular structures is well-known on postmortem studies, there is scant literature on imaging manifestations secondary to the vessel wall involvement, being confined mostly to isolated case reports and small series. The authors present a review of various cerebrovascular manifestations of neurosarcoidosis, along with a brief synopsis of the existing literature.
\end{abstract}

ABBREVIATIONS: $\mathrm{ICH}=$ intracerebral hemorrhage; NS = neurosarcoidosis

S arcoidosis is a noninfectious, idiopathic, inflammatory disorder that most frequently involves the lungs, skin, and lymph nodes. ${ }^{1}$ It is more common in African Americans and patients with Scandinavian ancestry and is characterized pathologically by formation of noncaseating granulomas. ${ }^{1} \mathrm{CNS}$ imaging findings in neurosarcoidosis (NS) are seen in about $10 \%$ of patients with systemic sarcoidosis. This is less than the incidence of CNS involvement on postmortem studies (15\%-25\%), but more than the incidence of symptomatic CNS involvement (approximately 5\%), implying that most patients with NS remain asymptomatic. ${ }^{1-4}$

Common imaging manifestations of NS include meningitis, parenchymal granulomas, white matter signal abnormalities, ventriculitis, hydrocephalus, and spinal involvement. ${ }^{1,5}$ These have been previously well-described. ${ }^{1,6}$ However, patients with NS may rarely present with cerebrovascular manifestations such as hemorrhage and stroke. These are thought to result from involvement of the arterial and venous structures and are only sporadically described in the literature, mostly through case reports and small case series. Although rare, these are of considerable importance, given the associated morbidity and mortality. Herein, the authors present a review of the existing literature on

From the Division of Neuroradiology (G.B., P.W., P.N.,T.M.), Department of Radiology, and Department of Pathology (S.G.), University of lowa Hospitals and Clinics, lowa City, lowa; and Division of Neuroradiology (S.M.), Department of Radiology, University of Pennsylvania, Philadelphia, Pennsylvania.

Please address correspondence to Girish Bathla, FRCR, MMeD, 3960 JPP, Department of Radiology, University of lowa Hospitals and Clinics, 200 Hawkins Dr, lowa City, IA 52246; e-mail: girish-bathla@uiowa.edu

- Indicates open access to non-subscribers at www.ajnr.org

http://dx.doi.org/10.3174/ajnr.A5492 the pathophysiology, pathology, and imaging findings of cerebrovascular manifestations of NS.

\section{Evolution and Pathogenesis}

The pathogenesis of sarcoidosis remains elusive, though it is generally believed that it represents an exaggerated response by a genetically predisposed individual to a specific-yet-unidentified antigen, which may be environmental or occupational. ${ }^{1}$ The scattered reports of occurrence of clusters of sarcoidosis (or sarcoidlike disease) in different population groups (health care workers, teachers, automobile manufacturers), including more recently in the firefighters exposed to World Trade Center "dust" during the collapse, again support some role for antigenic exposure. ${ }^{7}$

The offending antigens are likely airborne, which would explain the high incidence of lung involvement in sarcoidosis. Postmortem studies by Iwai et $\mathrm{al}^{8}$ demonstrated granulomatous dissemination by hematogenous and lymphatic routes as well as through local extension in the heart and lung. In the brain however, perivascular and vessel wall granulomas were the dominant feature. ${ }^{8-11}$ CNS involvement in systemic sarcoidosis is therefore presumably hematogenous, given the preferential perivascular distribution and paucity of a well-defined intracranial lymphatic system.

Besides the vascular involvement, postmortem studies have also documented prominent granulomatous involvement of the perivascular connective tissue, especially along the basal meninges, brain sulci, and the deep brain substance. ${ }^{8,12-14}$ The involvement of the deep gray nuclei likely results from extension along the lenticulostriate perforators or Virchow-Robin spaces. ${ }^{5,14,15}$ Over the cerebral convexities, the inflammation 

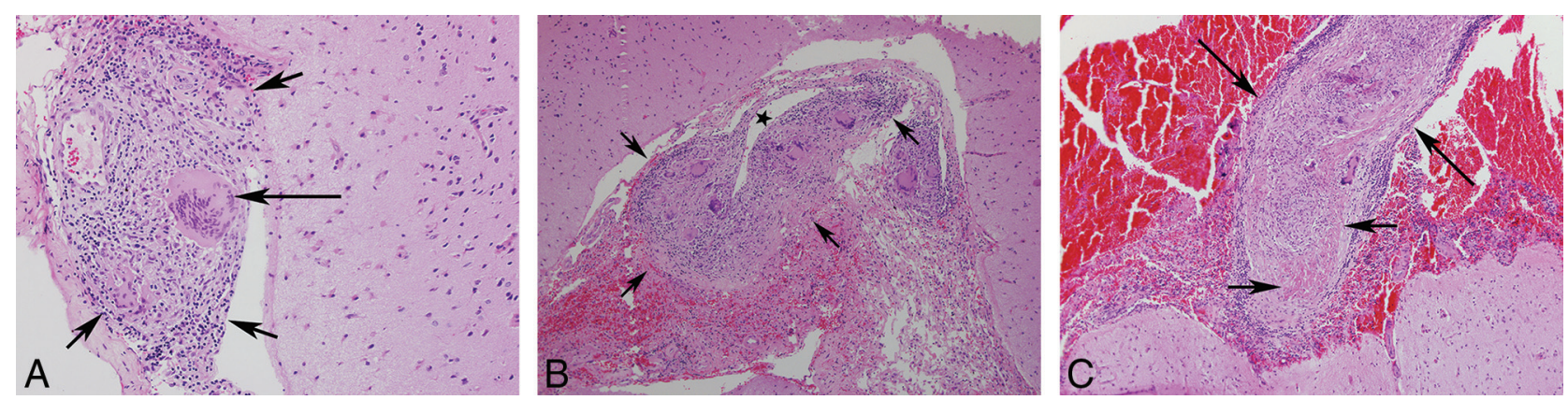

FIG 1. Brain biopsies from different patients showing typical sarcoid granuloma (short arrows) with a Langerhans-type giant cell (long arrow) $(\mathrm{H} \& \mathrm{E}$, original magnification $\times 20)(A)$, transmural granulomatous involvement of a meningeal vessel (short arrows, star represents the residual vessel lumen) (H\&E, original magnification $\times 20)(B)$, and granulomatous vessel wall involvement (long arrows) with fibrinoid necrosis (short arrows) (H\&E, original magnification $\times 10)(C)$.

again likely extends along the Virchow-Robin spaces into the cortex.

Although both arterial and venous involvement may be seen histopathologically, for unclear reasons, small arterial perforators are most frequently affected, ${ }^{12,14}$ while large-vessel involvement is the least common. Granulomatous phlebitis, on the contrary, most commonly involves the paraventricular veins along the lateral and third ventricles. ${ }^{12,14}$

Even though the pathophysiology remains unclear, the vascular effects are unlikely to be purely secondary to vessel wall infiltration. Some studies have previously demonstrated significantly increased CNS endothelial immunoglobulin G binding in patients with NS. ${ }^{16}$ Similarly, patients with sarcoidosis have also been shown to have impaired endothelial function and elevated arterial stiffness, which tends to parallel disease activity. ${ }^{17}$ Additionally, elevated levels of endothelin-1, a compound with a strong mitogenic potential for smooth-muscle cells and fibroblasts, have been noted during active disease. ${ }^{18}$ Finally, recent studies have also noted widespread endothelial damage in patients with sarcoidosis, even in the absence of granuloma formation. ${ }^{19}$ Quite possibly, the cerebrovascular manifestations of NS are multifactorial.

Vascular involvement may result in cerebral ischemia or parenchymal or subarachnoid hemorrhage. Involvement of the larger venous sinuses has been reported, manifesting as sinus thrombosis with or without parenchymal hemorrhage. Involvement of the bigger arterial vessels may result in large or even recurrent strokes. For unclear reasons, the latter is exceptionally rare. Most interesting, the entire circumference of a large vessel is rarely involved by the granulomatous inflammation on postmortem examination, unlike smaller vessels where the inflammation is more likely to be circumferential and transmural. ${ }^{13}$

\section{Histopathology}

The histopathologic understanding of sarcoidosis has evolved with time. The classic description of a sarcoid granuloma recognizes the characteristic morphology as discrete, compact, epithelioid cell granulomas with minimal or no necrosis (Fig 1). Although the presence of fibrinoid necrosis was reported in isolated postmortem studies, the use of the term "necrotizing sarcoid granulomatosis" as a diagnostic entity was only introduced in the pathology literature in 1973 by Liebow. ${ }^{20}$ Across time, these 2 relatively distinct morphologies have been thought to represent the 2 ends of a histopathologic continuum. Some authors now advocate the use of the term "sarcoidosis with necrotizing sarcoid granulomatosis pattern" to describe the variable extent of necrosis, instead of "necrotizing sarcoid granulomatosis."

Another distinctive histopathologic feature is granulomatous vasculitis/angiitis, characterized by infiltration of the vessel by the epithelioid cell granulomas. Although it was previously considered to be more common in the CNS, recent studies show that extra-CNS granulomatous vasculitis also occurs with equal frequency, though the extent of involvement may be variable. ${ }^{21}$ Vascular infiltration may result in destruction of a part of the wall by intramural or transmural granulomas or result in compressive obliteration without destruction. The third and less frequently described pattern consists of vessel wall destruction by infiltrate of lymphocytes, plasma cells, and histiocytes without discrete granulomas. ${ }^{22}$ When fibrinoid necrosis is present, the lesions can closely mimic the picture seen in polyarteritis nodosa, though unlike polyarteritis nodosa, the findings may be confined to the CNS. Although there are no distinct clinical or imaging subtypes of patients with necrotizing sarcoid granulomatosis and fibrinoid necrosis, isolated case reports with postmortem correlation do seem to suggest that the conditions of these patients may follow a more aggressive course. $9,14,23$

\section{Role of Imaging}

Traditionally, conventional angiography is considered the criterion standard for imaging vasculitis. However, because NS often involves the smaller perforating vessels and veins, it may not be well-evaluated. ${ }^{12,15,24}$ The utility of conventional angiography in patients with NS may therefore be limited to cases with largevessel involvement. MR imaging, on the other hand, often plays a leading role. Although MR imaging does not directly depict small vessels, the superior ability to identify small infarcts and microhemorrhages not only increases the sensitivity for underlying vasculitis but also gives it a distinct advantage over CT. Additionally, noninvasive MR imaging (or CT) angiography and venography can often provide sufficient information about larger vessels to preclude invasive angiography. Given the rarity of large-vessel involvement and the inherent risks of invasive angiography, contrast-enhanced MR imaging and MR angiography are likely to remain the preferred imaging tests for suspecting and diagnosing cerebrovascular involvement in NS. Although CTA has the slight advantage of superior spatial resolution, given the low incidence 
Table 1: Cases of NS with stroke in the reported English language literature ${ }^{a}$

\begin{tabular}{|c|c|c|c|c|c|c|c|c|}
\hline Author & Year & $\begin{array}{c}\text { Age } \\
(y r) / S e x\end{array}$ & $\begin{array}{l}\text { Zajicek } \\
\text { Criteria }\end{array}$ & CT/MRI & DWI & TIA & Stroke & $\begin{array}{c}\text { Systemic } \\
\text { Disease }\end{array}$ \\
\hline Brown et $a^{12}$ & 1989 & $25 / \mathrm{M}$ & Probable & $\mathrm{Y} / \mathrm{NS}$ & NS & $\mathrm{Y}$ & Left IC and corona radiata & $\mathrm{Y}$ \\
\hline Corse and Stern ${ }^{26}$ & 1990 & $38 / \mathrm{M}$ & Probable & $Y / Y$ & NS & Y & Right IC & Y \\
\hline Michotte et $\mathrm{al}^{4}$ & 1991 & $29 / M$ & Probable & $Y / Y$ & NS & $\mathrm{N}$ & Left BG, right frontal & Y \\
\hline Zadra et $\mathrm{al}^{24}$ & 1996 & $30 / \mathrm{M}$ & Probable & $\mathrm{Y} / \mathrm{Y}$ & NS & $\mathrm{N}$ & Multiple, anterior circulation & Y \\
\hline Das et $\mathrm{al}^{30}$ & 1998 & $27 / F$ & Probable & Y/NS & NS & $\mathrm{N}$ & Left MCA infarct & Y \\
\hline Brisman et $\mathrm{al}^{3}$ & 2006 & $41 / \mathrm{M}$ & Probable & $N S / Y$ & Y & $\mathrm{N}$ & Multiple, anterior circulation & Y \\
\hline Hodge et $\mathrm{al}^{2}$ & 2007 & $36 / \mathrm{F}$ & Definite & NS/Y & Y & $\mathrm{N}$ & Left BG & $\mathrm{N}$ \\
\hline Navi and DeAngelis ${ }^{31}$ & 2009 & $35 / \mathrm{M}$ & Definite & $N S / Y$ & $\mathrm{~N}$ & $\mathrm{~N}$ & Pons & $\mathrm{Y}$ \\
\hline Navi and DeAngelis ${ }^{31}$ & 2009 & $46 / F$ & Definite & $Y / Y$ & NS & $\mathrm{N}$ & Pons & Y \\
\hline González-Aramburu et al ${ }^{15}$ & 2012 & $27 / M$ & Probable & $\mathrm{Y} / \mathrm{Y}$ & Y & Y & Right IC and thalamus & Y \\
\hline Campbell et $\mathrm{al}^{32}$ & 2015 & $26 / M$ & Probable & $\mathrm{Y} / \mathrm{Y}$ & Y & Y & Left centrum semiovale & Y \\
\hline Raza and Schreck ${ }^{25}$ & 2017 & $73 / \mathrm{F}$ & Probable & NS/Y & NS & $\mathrm{N}$ & Recurrent left MCA strokes & Y \\
\hline Macedo et $\mathrm{al}^{5}$ & 2016 & $62 / \mathrm{M}$ & Possible & $Y / Y$ & Y & $\mathrm{Y}$ & Multiple, anterior/posterior circulation & Y \\
\hline
\end{tabular}

Note:-BG indicates basal ganglia; IC, internal capsule; N, no; NS, not specified; Y, yes.

${ }^{a}$ On the basis of the Zajicek criteria, ${ }^{1}$ cases may be definite (neural tissue biopsy), probable (presence of CNS inflammation with evidence of systemic disease), or possible (clinical presentation consistent with NS with exclusion of alternate diagnosis).
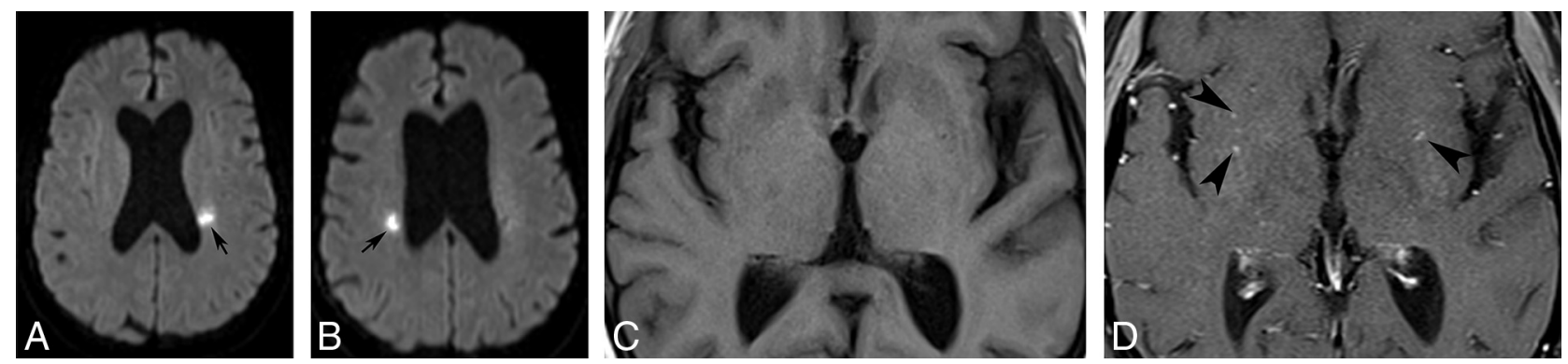

FIG 2. Axial DWIs at the level of the corona radiata obtained at 2 different time points $(A$ and $B)$ show recurrent periventricular infarcts. Axial magnified pre- $(C)$ and postcontrast $(D)$ images reveal subtle perivascular enhancement involving the bilateral basal ganglia (arrowheads, $D$ ).

of large-vessel vasculitis, it is unclear whether it adds any substantial value over MRA, which can be combined with an MR imaging study in a single session.

\section{Ischemic Lesions}

Ischemic insults in NS are intriguingly rare, despite the frequent granulomatous vascular infiltration on postmortem studies. ${ }^{3,4,12,15,25}$ The exact mechanism of infarction is likely multifactorial, resulting from a combination of small-vessel vasculitis, large-vessel inflammation, or cardioembolic phenomenon secondary to sarcoid cardiomyopathy. ${ }^{2,26}$ Because perforating arteries are most frequently involved, the infarcts are often small and commonly involve the basal ganglia, thalamus, and brain stem, though large-vessel and recurrent infarcts may also occur. ${ }^{25}$

In the pre-CT era, most of the infarcts were diagnosed on postmortem studies. Commonly, these did not have a documented antemortem presentation. ${ }^{14,23,27-29}$ It is unclear whether the infarcts were clinically silent due to their small size or were overshadowed by the clinical manifestations of meningism, neurologic deficits, and hydrocephalus known to accompany NS. These predominantly involved the distribution of perforating arteries. Most of the described patients were young and male and had concurrent extracranial sarcoidosis.

At times, the ischemic insults in NS may be symptomatic and present as acute stroke with or without a preceding transient ischemic attack, or even as recurrent TIAs without stroke. ${ }^{2,5,10,25,26}$ Table 1 lists the cases of acute stroke reported in patients with NS in the English language literature. ${ }^{2-5,12,15,24-26,30-32}$ Like the asymp- tomatic infarcts, most of the patients were young and nearly all had coexisting extracranial disease. Also, unlike sarcoidosis, which has a female predilection, cases with cerebrovascular findings showed a male predilection.

Given the existing literature, one may therefore expect to see both silent and symptomatic lesions on imaging, which is concordant with the institutional experience of the authors. The infarcts are often small and may be most apparent on diffusion-weighted images as foci of restricted diffusion, often in the deep brain substance. T2-weighted images may not be very useful and any surrounding parenchymal edema or white matter lesions tend to make them even more inconspicuous. Occasionally, the infarcts may be multiple, recurrent, or of varying ages (Fig 2). ${ }^{4,25}$ Rarely, lesions may be more superficial and subcortical, occurring secondary to involvement of the cortical vessels from surrounding meningeal inflammation (Fig 3). Although the presence of infarcts by itself is not specific for underlying NS, its occurrence, especially in young patients with coexisting intracranial findings of NS or known systemic sarcoidosis, may point to an underlying granulomatous etiology. Rarely, an ischemic insult may be the first manifestation of isolated NS without systemic involvement. ${ }^{2}$ In such cases, the diagnosis may be especially challenging and eventually require histopathologic confirmation.

Large-vessel strokes in NS are exceptionally rare, as can be expected from the less severe and noncircumferential vessel wall involvement on pathology. ${ }^{13,25,26}$ MRA or conventional angiography in such cases may show focal vascular stenosis or occlu- 
sion. ${ }^{4,5,15,26}$ A Moyamoya-like vasculopathy pattern has also been reported in association with NS and may be unilateral or bilateral. ${ }^{33}$ Because the underlying etiology is vasculitis, one may see changes of both ischemia and hemorrhage in these patients at different time points (Fig 4).

In patients with ischemic strokes, the differential considerations include both embolic and nonembolic etiologies. Cardioembolic infarcts secondary to atheromatous disease are possible
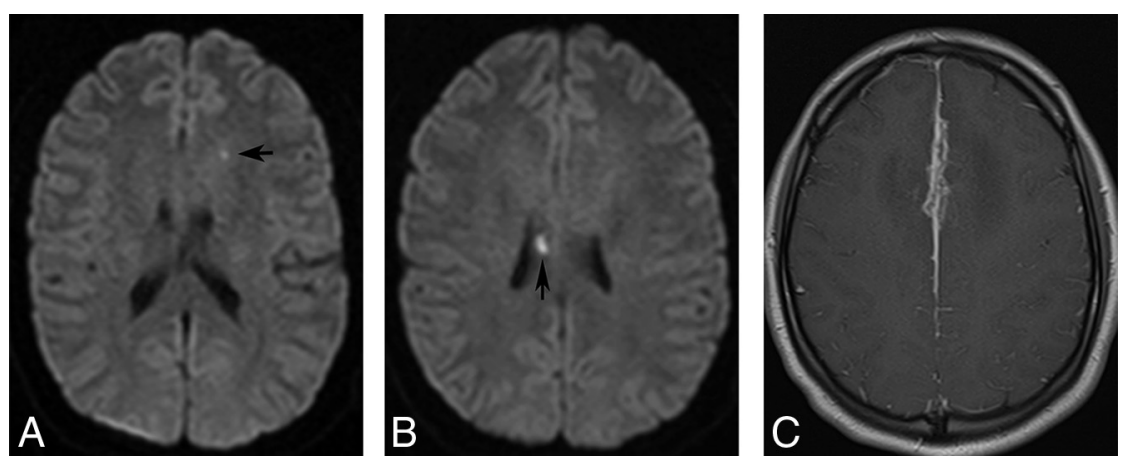

FIG 3. Axial DWIs reveal tiny subcortical infarcts $(A$ and $B)$ in a 22 -year-old female patient. Axial postcontrast image $(C)$ shows prominent involvement of the midline falx anteriorly. The infarcts were presumably secondary to involvement of the cortical vessels.
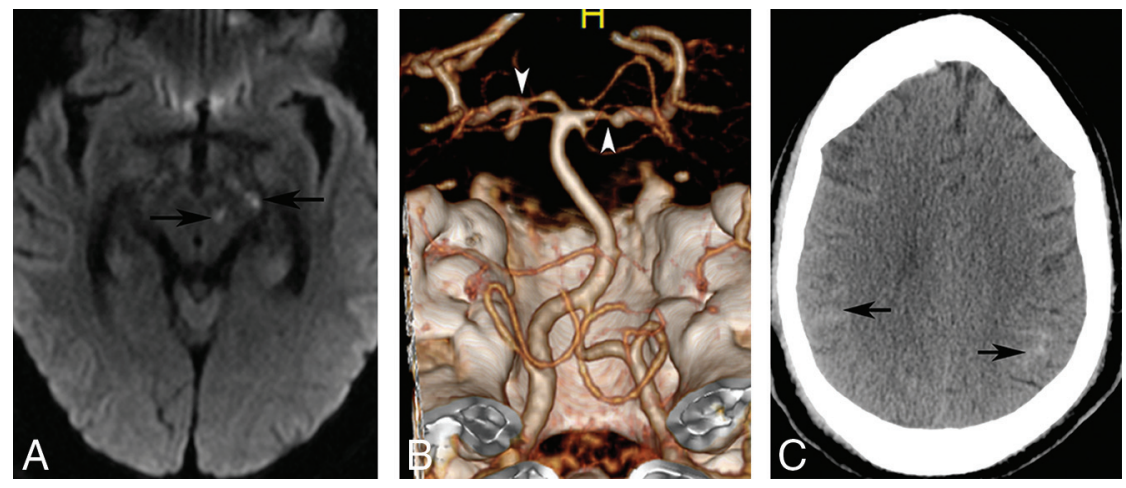

FIG 4. Axial DWI $(A)$ in a 38-year-old male patient with NS reveals punctate infarcts involving the left cerebral peduncle and midbrain (arrows). A volume-rendered CT angiogram shows multifocal stenoses involving the P1 segments of the bilateral posterior cerebral arteries $(B)$. The patient again presented after 2 months with severe headache. Noncontrast CT (C) image at this time shows acute subarachnoid hemorrhage over bilateral parietal convexities (arrows). but are statistically less likely among younger populations. The leading nonembolic consideration is the primary angiitis of the CNS, which can closely mimic vasculitis of NS on histopathology. Primary angiitis of the CNS, however, commonly affects patients in middle age, has an aggressive clinical course, and is confined to the CNS, unlike NS which invariably has extracranial disease. Additionally, primary angiitis of the CNS often has abnormal angiographic findings, reported in up to $50 \%-90 \%$ of patients. ${ }^{34}$

CNS vasculitis may also be seen in association with collagen vascular diseases, drug abuse, or underlying infectious (HIV, herpes simplex virus, syphilis) or inflammatory lesions (Behçet disease, polyarteritis nodosa, Wegener disease). ${ }^{35}$ In these cases, the constellation of clinical and imaging findings, presence of known systemic disease, or history of drug abuse may help narrow the differential considerations.

\section{Hemorrhagic Lesions}

Hemorrhagic lesions in NS are also rare, with a reported incidence of $0.6 \%$ in unselected sarcoidosis and series of patients with NS. ${ }^{36,37}$ Because the common denominator in both ischemic and hemorrhagic lesions is underlying vasculitis, it is not surprising that they both have a male predilection, unlike sarcoidosis, which is more common in females. ${ }^{36,38,39}$

Table 2 lists the cases of NS with intracerebral hemorrhage (ICH) reported in the English language literature where imaging was performed. ${ }^{28,36-47}$ A review of these cases reveals that $\mathrm{ICH}$ in patients with NS is often intraparenchymal and is more likely to be supratentorial. Rarely, patients may also present with

Table 2: Cases of NS with ICH in the reported English language literature

\begin{tabular}{|c|c|c|c|c|c|c|c|}
\hline Author & Year & $\begin{array}{c}\text { Age } \\
(y r) / S e x\end{array}$ & $\begin{array}{l}\text { Zajicek } \\
\text { Criteria }\end{array}$ & $\mathrm{CT} / \mathrm{MRI}$ & MRA/DSA & Site & $\begin{array}{c}\text { Systemic } \\
\text { Disease }\end{array}$ \\
\hline Caplan et $\mathrm{al}^{28}$ & 1983 & $21 / \mathrm{M}$ & Probable & $\mathrm{Y} / \mathrm{NS}$ & NS & Left cerebellar & $\mathrm{Y}$ \\
\hline Oksanen ${ }^{46}$ & 1986 & NS/NS & NS & NS/NS & NS & NS & NS \\
\hline Oksanen $^{46}$ & 1986 & NS/NS & NS & NS/NS & NS & NS & NS \\
\hline Berek et $\mathrm{al}^{40}$ & 1993 & $35 / \mathrm{M}$ & Possible & $\mathrm{Y} / \mathrm{Y}$ & Nm DSA & SAH on LP & $\mathrm{N}$ \\
\hline Libman et $\mathrm{al}^{42}$ & 1997 & $48 / \mathrm{F}$ & Probable & $Y / Y$ & + DSA & Multiple, left cerebral hemisphere & Y \\
\hline Eid et $\mathrm{al}^{43}$ & 1998 & $31 / \mathrm{F}$ & Probable & Y/NS & + DSA & Right frontal & Y \\
\hline Cipri et $\mathrm{al}^{47}$ & 2000 & $31 / \mathrm{M}$ & Definite & $Y / Y$ & Nm DSA & Right occipital & $\mathrm{N}$ \\
\hline Dakdouki et $\mathrm{al}^{45}$ & 2005 & $25 / \mathrm{M}$ & Probable & NS/Y & NS & Pons & Y \\
\hline Tsappidi et $\mathrm{al}^{38}$ & 2011 & $43 / M$ & Definite & $Y / Y$ & $\mathrm{Nm}$ DSA/MRA & Multiple, supratentorial & $\mathrm{N}$ \\
\hline O'Dwyer et $\mathrm{al}^{36}$ & 2013 & $41 / M$ & Definite & $Y / Y$ & $\mathrm{Nm}$ CTA & Cerebellum & $\mathrm{N}$ \\
\hline O'Dwyer et $\mathrm{al}^{36}$ & 2013 & $41 / \mathrm{M}$ & Probable & $Y / Y$ & $\mathrm{Nm}$ MRA & Pontomesecephalic & Y \\
\hline O'Dwyer et $\mathrm{al}^{36}$ & 2013 & $36 / \mathrm{M}$ & Probable & $Y / Y$ & Nm DSA & Left frontal & Y \\
\hline Travers et al ${ }^{44}$ & 2014 & $37 / \mathrm{M}$ & Probable & NS/Y & $\mathrm{Nm}$ & Right temporal & Y \\
\hline Pegat et $\mathrm{al}^{41}$ & 2015 & $48 / \mathrm{F}$ & Probable & NS/Y & NS & Left frontoparietal & Y \\
\hline Vargas et $\mathrm{al}^{37}$ & 2016 & $62 / F$ & Probable & $Y / Y$ & Nm MRA & Multiple microhemorrhages & Y \\
\hline Vukojević et al ${ }^{39}$ & 2017 & $45 / \mathrm{F}$ & Probable & $\mathrm{Y} / \mathrm{Y}$ & $\mathrm{Nm}$ CTA & Multiple, supra- and infratentorial & Y \\
\hline
\end{tabular}

Note:-Nm indicates normal findings; LP, lumbar puncture; N, no; NS, not specified; Y, yes; +, positive. 

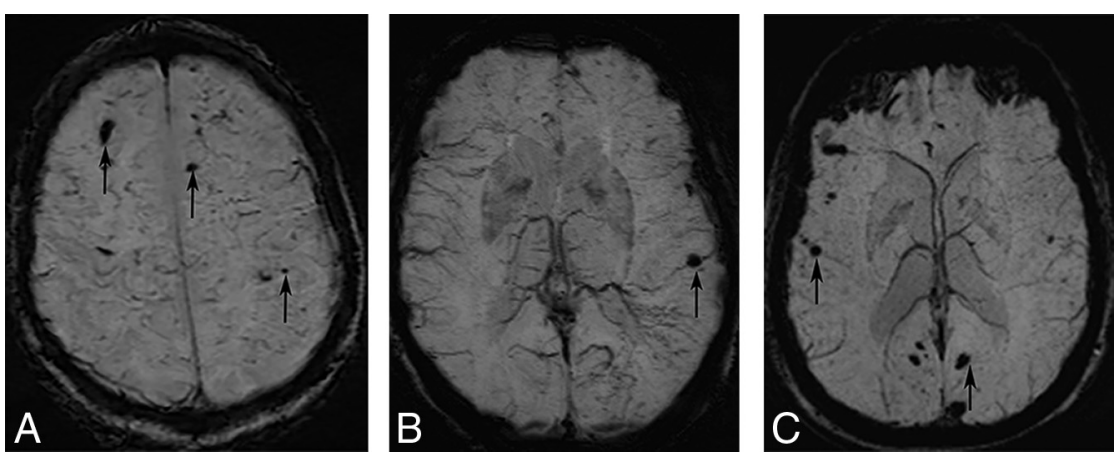

FIG 5. Axial SWI at the level of centrum semiovale $(A)$ and basal ganglia $(B)$ from 1 patient and at the level of basal ganglia in the other patient $(C)$. There are multiple scattered foci of susceptibility involving bilateral subcortical white matter (arrows) with relative sparing of the basal ganglia in both patients.
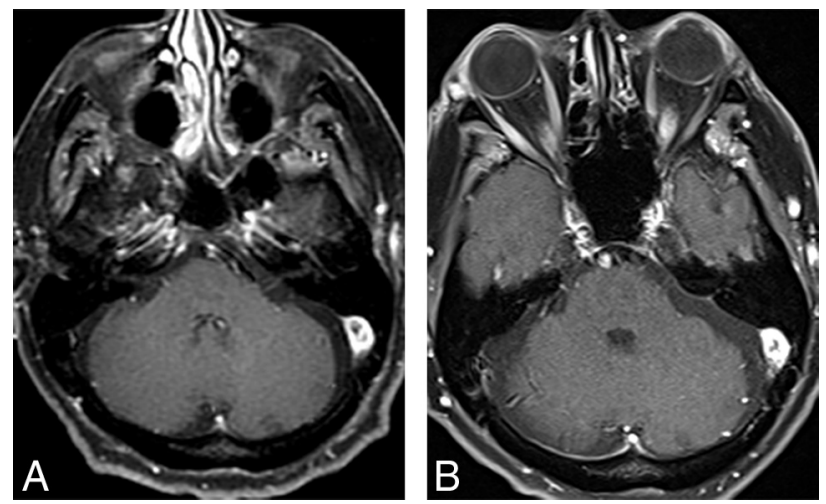

FIG 6. $A$ and $B$, Axial postcontrast images through the posterior fossa obtained over an interval of 10 years. The prominent left sigmoid sinus enhancement remains essentially unchanged. The patient also had superior sagittal sinus involvement (not shown).

subarachnoid hemorrhage. ${ }^{40}$ For unclear reasons, patients with symptomatic ICH seem to have a lobar predilection. This is somewhat counterintuitive because perivascular involvement in NS is most prominent in the basal ganglia, brain stem, and spinal cord. ${ }^{12-14}$ Isolated postmortem reports in patients with NS with ICH have also documented hemorrhages in the basal ganglia and posterior fossa compared with the cerebral hemispheres. ${ }^{14,28} \mathrm{Al}-$ though some of the apparent lobar predilection may be from a reporting bias of larger symptomatic lesions, the reasons for relative sparing of the basal ganglia in the reported studies are unclear and unlikely to be entirely coincidental. Like some of the recently reported cases ${ }^{37,39,42}$ and the authors' personal experiences, distinct peripheral distribution of the ICH with sparing of the basal ganglia may be seen, though its significance is not clear (Fig 5).

The overall heterogeneity of the lesion distribution may be secondary to pathologically demonstrated "mixed" venous and arterial involvement. ${ }^{36}$ As may be expected with predominantly small-vessel involvement, hemorrhagic lesions in patients with NS are often small and may be microhemorrhagic, though large parenchymal hematomas do rarely occur. ${ }^{36,37,43}$ Similar to ischemic strokes, multiple or recurrent hemorrhages may also be seen. ${ }^{37,39,42}$ Also analogous to cases with ischemic lesions, angiographic studies (DSA/MRA/CTA) are often unyielding. As shown in Table 2, of the 11 cases in which an angiographic evaluation was performed, positive findings were only noted in 2 cases.

The initial diagnosis of NS in patients presenting with ICH can be very challenging, especially because almost half of these patients may not have known sarcoidosis. ${ }^{46}$ Although it has been previously reported that about $31 \%$ of these patients have isolated NS, as noted in Table 2, most of these patients do have extra-CNS manifestations, though they may not be symptomatic. ${ }^{36}$ Nevertheless, atypical locations of hemorrhage or multiple smaller or microhemorrhagic lesions, especially in the presence of other imaging signs of NS, should raise the suspicion in the appropriate clinical setting. ${ }^{36,44}$

There is scarce literature on the impact of immunosuppressive therapy on patients with ischemic lesions. However, cases with hemorrhagic lesions do appear responsive to early aggressive antigranulomatous therapy, an important consideration because the microhemorrhages tend to increase with time and have been anecdotally associated with cognitive decline. ${ }^{36,37} \mathrm{An}$ increase in intraparenchymal hemorrhages associated with steroid tapering or discontinuation has also been reported in multiple recent cases, highlighting the need for close follow-up while tapering immunosuppressive therapy. ${ }^{37,39,44,45}$

The primary differential consideration of ICH in NS includes vasculitis, especially primary angiitis of the CNS, as discussed previously. Similar to the NS patients with ischemic lesions, the angiographic studies in patients with ICH are also often negative, though some cases may show large vessel vasculitis. ${ }^{36,42,43,46}$ Other differential considerations may include cerebral amyloid angiopathy, hypertensive angiopathy, and cerebral autosomal dominant arteriopathy with subcortical infarcts and leukoencephalopathy, though these tend to affect older patients in the first 2 instances and often have a predilection for the temporal lobes and external capsule in the latter. ${ }^{37}$

\section{Dural Sinus Involvement}

Dural sinus thrombosis in NS is exceptionally rare, with only 5 cases reported in the literature. ${ }^{48-52}$ The underlying mechanism is unclear and is presumably secondary to granulomatous meningeal involvement. ${ }^{51,52}$ Most patients present with symptoms of raised intracranial pressure. Given the rare occurrence, there is limited available imaging literature. The superior sagittal sinus is most frequently involved. Byrne and Lawton ${ }^{49}$ reported a case of meningeal sarcoidosis in a 32-year-old woman with an obstructed straight sinus and bilateral transverse sinuses on angiography. They also noted meningeal enhancement along the occluded sinuses without any change in appearance on follow-up imaging at 5 years. The patient had imaging findings of intracranial hypertension, including an empty sella and erosion of the dorsum sella.

Leeds et a ${ }^{52}$ presented a case of superior sagittal sinus thrombosis, which they attributed to surrounding granulomatous inflammation. However, the images were presented as a part of 

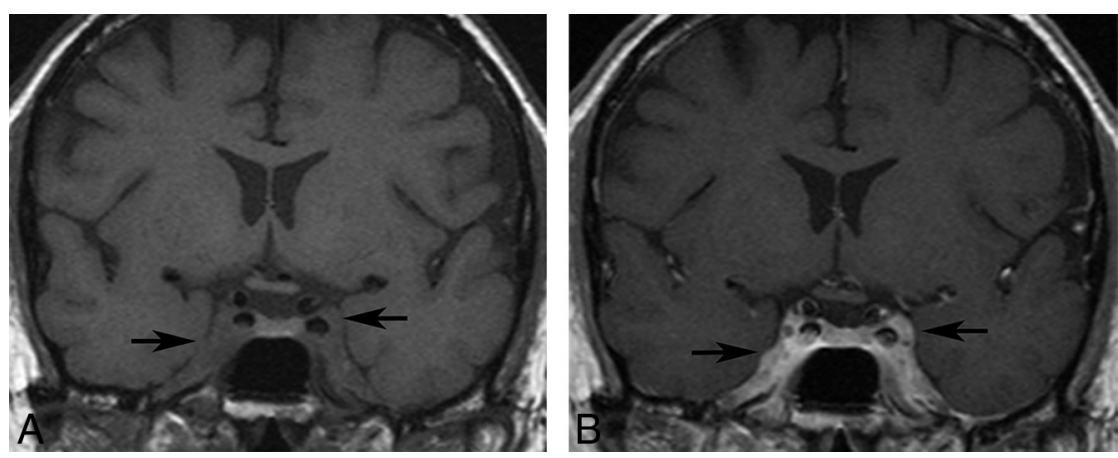

extra-CNS findings of sarcoidosis may be the only helpful clue in such cases.

\section{CONCLUSIONS}

The authors present a review of the various cerebrovascular manifestations that may be encountered in patients with NS. Although rare, these are of utmost importance, not only because of the associated morbidity but also because patients may present with isolated NS and pose considerable diagnostic challenges, especially when the manifestations are atypical. Vasculitic manifestations of NS should be considered in patients with recurrent hemorrhages or infarcts, espeand enhancement of the cavernous sinuses bilaterally. The patient had additional intracranial stigmata of NS (not shown), and the cavernous sinus involvement was presumed to be secondary to NS.

an imaging review article with no additional patient-specific details. Chapelon et $\mathrm{al}^{51}$ also reported a case of a 26-year-old man with NS and superior sagittal sinus thrombosis in their review of 35 patients without much additional information. ${ }^{51}$ Akova et $\mathrm{al}^{48}$ presented a case report of possible NS in a 35-year-old man with superior sagittal sinus thrombosis associated with meningeal sarcoidosis and clinical features of pseudotumor cerebri.

More recently, Degardin et $\mathrm{al}^{50}$ presented a case of a 47 -yearold man with superior sagittal sinus thrombosis. They also noted that the thrombosis persisted at 6-month follow-up despite satisfactory anticoagulation. The patient also had large-vessel involvement as well as multiple intraparenchymal hemorrhages of varying ages, which were attributed to granulomatous angiitis. We also encountered a similar case of thrombosis in a 61-year-old male patient involving the sagittal and left transverse sinuses over a background of multiple intraparenchymal hemorrhages of varying ages. Our patient also showed a persistently enlarged and enhancing sinus with surrounding collaterals that remained unchanged for 10 years (Fig 6). This feature contrasts with a bland thrombus, which is usually dissolved with anticoagulation, leaving behind a normal or attenuated vessel and a collateral network. The persistent imaging findings are possibly from continued granulomatous sinus involvement.

\section{Cavernous Sinus Involvement}

Cavernous sinus involvement in NS is again exceedingly rare, with only 2 prior reported cases. ${ }^{53,54}$ Chang et $\mathrm{al}^{53}$ reported a case of left cavernous sinus involvement in a 54-year-old man with concurrent pulmonary sarcoidosis. The other reported case was by Kim et $\mathrm{al}^{54}$ of a 40 -year-old man with NS localized to the right cavernous sinus without any additional CNS or extra-CNS involvement. In both cases, the imaging findings were nonspecific and showed a T1-isointense, T2-hyperintense, enhancing cavernous sinus mass. We also encountered a case like that of Chang et al with nodular thickening of the cavernous sinus, most apparent on the contrast-enhanced images (Fig 7). Overall, the rarity of cavernous sinus involvement, the scarcity of literature, and nonspecific imaging findings preclude any meaningful conclusions about the expected MR imaging findings.

The differential considerations in such cases are invariably broad and include neoplasms, infective lesions, or inflammatory conditions such as Tolosa-Hunt syndrome. Coexisting CNS or cially when the patients are younger and demonstrate additional intracranial imaging findings that may support NS.

Disclosures: Suyash Mohan-UNRELATED: Grants/Grants Pending: Novocure, Radiological Society of North America, Guerbet, Comments: research grants* * Money paid to the institution.

\section{REFERENCES}

1. Bathla G, Singh AK, Policeni B, et al. Imaging of neurosarcoidosis: common, uncommon, and rare. Clin Radiol 2016;71:96-106 CrossRef Medline

2. Hodge MH, Williams RL, Fukui MB. Neurosarcoidosis presenting as acute infarction on diffusion-weighted MR imaging: summary of radiologic findings. AJNR Am J Neuroradiol 2007;28:84-86 Medline

3. Brisman JL, Hinduja A, McKinney JS, et al. Successful emergent angioplasty of neurosarcoid vasculitis presenting with strokes. Surg Neurol 2006;66:402-04 CrossRef Medline

4. Michotte A, Dequenne P, Jacobovitz D, et al. Focal neurological deficit with sudden onset as the first manifestation of sarcoidosis: a case report with MRI follow-up. Eur Neurol 1991;31:376-79 Medline

5. Macedo PJ, da Silveira VC, Ramos LT, et al. Isolated central nervous system vasculitis as a manifestation of neurosarcoidosis. J Stroke Cerebrovas Dis 2016;25:e89-e92 CrossRef Medline

6. Smith JK, Matheus MG, Castillo M, et al. Imaging manifestations of neurosarcoidosis. AJR Am J Roentgenol 2004;182:289-95 CrossRef Medline

7. Izbicki G, Chavko R, Banauch GI, et al. World Trade Center "sarcoid-like" granulomatous pulmonary disease in New York City Fire Department rescue workers. Chest J 2007;131:1414-23 CrossRef Medline

8. Iwai K, Takemura T, Kitalchi M, et al. Pathological studies on sarcoidosis autopsy, II: early change, mode of progression and death pattern. Acta Pathol Jpn 1993;43:377-85 Medline

9. Robert F. Sarcoidosis of the central nervous system: report of a case and review of the literature. Arch Neurol 1962;7:442-49 CrossRef Medline

10. Duffey $P$, Bates D. Transient focal neurological deficit in sarcoidosis. Sarcoidosis Vasc Diffuse Lung Dis 1997;14:171-72 Medline

11. Camp WA, Frierson JG. Sarcoidosis of the central nervous system: a case with postmortem studies. Arch Neurol 1962;7:432-41 CrossRef Medline

12. Brown MM, Thompson AJ, Wedzicha JA, et al. Sarcoidosis presenting with stroke. Stroke 1989;20:400-05 CrossRef Medline

13. Reske-Nielsen E, Harmsen A. Periangiitis and panangiitis as a manifestation of sarcoidosis of the brain: report of a case. J Nerv Ment Dis 1962;135:399-412 CrossRef Medline

14. Herring $A B$, Urich $H$. Sarcoidosis of the central nervous system. J Neurol Sci 1969;9:405-22 CrossRef Medline

15. González-Aramburu I, Ruiz-Pérez E, Gómez-Román J, et al. Sarcoid- 
osis presenting as transient ischemic attack status. J Stroke Cerebrovasc Dis 2012;21:515-17 CrossRef Medline

16. Tsukada N, Yanagisawa N, Mochizuki I. Endothelial cell damage in sarcoidosis and neurosarcoidosis: autoantibodies to endothelial cells. Eur Neurol 1995;35:108-12 Medline

17. Siasos G, Tousoulis D, Gialafos E, et al. Association of sarcoidosis with endothelial function, arterial wall properties, and biomarkers of inflammation. Am J Hypertens 2011;24:647-53 CrossRef Medline

18. Letizia C, Danese A, Reale MG, et al. Plasma levels of endothelin-1 increase in patients with sarcoidosis and fall after disease remission. Panminerva Med 2001;43:257-61 Medline

19. Mochizuki I, Kubo K, Hond T. Widespread heavy damage of capillary endothelial cells in the pathogenesis of sarcoidosis: evidence by monoclonal von Willebrand factor immunohistochemistry in the bronchus and lung of patients with sarcoidosis. Sarcoidosis Vasc Diffuse Lung Dis 2014;31:182-90 CrossRef Medline

20. Liebow AA. The J Burns Amberson lecture: pulmonary angiitis and granulomatosis. Am Rev Respir Dis 1973;108:1-18 Medline

21. Rosen Y. Four decades of necrotizing sarcoid granulomatosis: what do we know now? Arch Pathol Lab Med 2015;139:252-62 CrossRef Medline

22. Churg A, Carrington CB, Gupta R. Necrotizing sarcoid granulomatosis. Chest 1979;76:406-13 CrossRef Medline

23. Manz HJ. Pathobiology of neurosarcoidosis and clinicopathologic correlation. Can J Neurol Sci 1983;10:50-55 CrossRef Medline

24. Zadra M, Brambilla A, Erli LC, et al. Neurosarcoidosis, stroke and antiphospholipid antibodies: a case report. Eur J Neurol 1996;3: 146-48 CrossRef

25. Raza N, Schreck KC. Neurosarcoidosis presenting with recurrent strokes: a case report and literature review. Neurohospitalist 2017;7: 91-95 CrossRef Medline

26. Corse AM, Stern BJ. Neurosarcoidosis and stroke. Stroke 1990;21: 152-53 Medline

27. Schonell ME, Gillespie WJ, Maloney AF. Cerebral sarcoidosis. $\mathrm{Br} J$ Dis Chest 1968;62:195-99 CrossRef Medline

28. Caplan L, Corbett J, Goodwin J, et al. Neuro-ophthalmologic signs in the angiitic form of neurosarcoidosis. Neurology 1983;33:1130-35 CrossRef Medline

29. Meyer JS, Foley JM, Campagna-Pinto D. Granulomatous angiitis of the meninges in sarcoidosis. AMA Arch Neurol Psychiatry 1953;69: 587-600 CrossRef Medline

30. Das SK, Sinha I, Kundu TN, et al. Two cases of neurosarcoidosis presenting as peripheral neuropathy and stroke in young. $J$ Assoc Physicians India 1998;46:479-81 Medline

31. Navi BB, DeAngelis LM. Sarcoidosis presenting as brainstem ischemic stroke. Neurology 2009;72:1021-22 CrossRef Medline

32. Campbell J, Kee R, Bhattacharya D, et al. Systemic sarcoidosis presenting with headache and stroke-like episodes. Case Rep Immunol 2015;2015:619867 CrossRef Medline

33. Ko JK, Lee SW, Choi CH. Moyamoya-like vasculopathy in neurosarcoidosis. J Korean Neurosurg Soc 2009;45:50-52 CrossRef Medline

34. Birnbaum J, Hellmann DB. Primary angiitis of the central nervous system. Arch Neurol 2009;66:704-09 CrossRef Medline

35. Grossman RI, Yousem DM. Neuroradiology: The Requisites. St Louis: Mosby; 2003:196-204
36. O'Dwyer JP, Al-Moyeed BA, Farrell MA, et al. Neurosarcoidosisrelated intracranial haemorrhage: three new cases and a systematic review of the literature. Eur J Neurol 2013;20:71-78 CrossRef Medline

37. Vargas A, Gorelick PB, Testai FD. Progressive central nervous system vasculopathy in sarcoidosis: a case report. J Neurol Sci 2016;362: 153-54 CrossRef Medline

38. Tsappidi S, Hui F, Turan TN, et al. Intracerebral hemorrhage: an unusual presentation of neurosarcoidosis. Neurologist 2011;17: 292-96 CrossRef Medline

39. Vukojević Z, Ilić TV, Dominović-Kovačević A, et al. Neurosarcoidosis and multiple intracerebral hematomas: an unusual clinical presentation. J Neurol Sci 2017;379:22-24 CrossRef Medline

40. Berek K, Kiechl S, Willeit J, et al. Subarachnoid hemorrhage as presenting feature of isolated neurosarcoidosis. Clin Investig 1993;71: 54-56 Medline

41. Pegat B, Drapier S, Morandi X, et al. Spinal cord hemorrhage in a patient with neurosarcoidosis on long-term corticosteroid therapy: case report. BMC Neurol 2015;15:123 CrossRef Medline

42. Libman RB, Sharfstein S, Harrington W, et al. Recurrent intracerebral hemorrhage from sarcoid angiitis. J Stroke Cerebrovasc Dis 1997;6:373-75 CrossRef Medline

43. Eid H, O'Connor CR, Catalano $\mathrm{E}$, et al. Life-threatening vasculitis associated with sarcoidosis. J Clin Rheumatol 1998;4:338-43 CrossRef Medline

44. Travers F, Maltête D, Morisse-Pradier H. Intracranial hemorrhage in neurosarcoidosis. J Neurol Sci 2014;341:185-86 CrossRef Medline

45. Dakdouki GK, Kanafani ZA, Ishak G, et al. Intracerebral bleeding in a patient with neurosarcoidosis while on corticosteroid therapy. South Med J 2005;98:492-95 CrossRef Medline

46. Oksanen V. Neurosarcoidosis: clinical presentations and course in 50 patients. Acta Neurol Scand 1986;73:283-90 Medline

47. Cipri S, Gambardella G, Campolo C, et al. Unusual clinical presentation of cerebral-isolated sarcoidosis: case report and review of the literature. J Neurosurg Sci 2000;44:140-44 Medline

48. Akova YA, Kansu T, Duman S. Pseudotumor cerebri secondary to dural sinus thrombosis in neurosarcoidosis. J Clin Neuroophthalmol 1993;13:188-89 Medline

49. Byrne JV, Lawton CA. Meningeal sarcoidosis causing intracranial hypertension secondary to dural sinus thrombosis. BrJ Radiol 1983; 56:755-57 CrossRef Medline

50. Degardin A, Devos P, Vermersch P, et al. Cerebrovascular symptomatic involvement in sarcoidosis. Acta Neurol Belg 2010;110:349-52 Medline

51. Chapelon C, Ziza JM, Piette JC, et al. Neurosarcoidosis: signs, course and treatment in 35 confirmed cases. Medicine 1990;69:261-76 CrossRef Medline

52. Leeds NE, Zimmerman RD, Elkin CM, et al. Neurosarcoidosis of the brain and meninges. Semin Roentgenol 1985;20:387-92 CrossRef Medline

53. Chang CS, Chen WL, Li CT, et al. Cavernous sinus syndrome due to sarcoidosis: a case report. Acta Neurol Taiwan 2009;18:37-41 Medline

54. Kim DH, Cho WH, Cho KS, et al. Solitary cavernous sinus neurosarcoidosis mimicking neurosyphilis. J Korean Neurosurg Soc 2014; 55:61-63 CrossRef Medline 